\title{
Posterior longitudinal bağ ossifikasyonunun cerrahi tedavisi: anterior yaklaşım
}

\section{Surgical treatment of posterior longitudinal ligament ossification: anterior approach}

\author{
Görkem Kıyak¹, Murat Bezer² \\ 1 Academic Hospital Hastanesi, İstanbul \\ 2̇̇stanbul Marmara Ünivertsitesi Tıp Fakültesi, Ortopedi ve Travmatoloji Anabilim Dalı, İstanbul
}

Posterior longitudinal bağ (ligament) ossifikasyonu (PLLO), bağın fibroblast dokusunun zamanla ektopik yeni kemik dokusu ile yer değiştirmesiyle oluşur. En sık olarak, C4-C5 seviyesindeki ossifiye doku kalınlaşmaya başladıkça spinal kanal içinde yer kaplayıcı lezyon etkisi yaratır ve bu da, spinal kanalın daralması sonucu nörolojik bulguların ortaya çıkmasına neden olur. Doğu Asya kökenli insanlarda daha sık görüldüğü için, bu hastalık üzerine yapılan ilk araştırmalar da Japonya ve Kore gibi ülkelerden çıkmıştır. Japonya'da yapılan çalışmalarda, servikal bir rahatsızlıkla hastanelere başvuranlar arasında görülme sıklığı \%1,9 ile \%4,3 arasında değişmektedir. ${ }^{[1]}$ Kuzey Amerika ve Avrupa popülasyonunda ise görülme sıklığı daha düşüktür. Bildirilen insidans oranları $\% 0,1$ ile \%1,7 arasında değişmektedir. ${ }^{[2,3]}$ Bu bölümde servikal PLL ossifikasyonuna anterior yaklaşım tartışılacaktır.

Anahtar sözcükler: servikal anterior; ligaman ossifikasyonu; dekompresyon
Ossification of the posterior longitudinal ligament (OPLL) occurs when the fibroblast tissue of ligament is displaced in time by ectopic new bone tissue. Most commonly, C4C5 level of ossifiying tissue begins to thicken to create a spinal lesion in the spinal canal, and consequently narrowing of the spinal canal leads to neurological symptoms. As it is more common in people of Eastern Asiatic origin, foregoing researches on this disease were seen in countries such as Japan and Korea. In Japan, the incidence of cervical complaints among hospitals is between $1.9 \%$ and 4.3\%. The incidence is lower in the North American and European populations; reported rates range from $0.1 \%$ to $1.7 \%$. In this section, the anterior approach to cervical OPLL will be discussed.

Key words: cervical anterior; ligament ossification; decompression

\section{P} osterior longitudinal bağ (PLL), C1'den sakruma kadar uzanan ve vertebral korpusların dorsal yüzeyini kaplayan bağ dukusunu tanımlar. Fonksiyonel olarak, omurganın aşırı fleksiyonuna direnç gösteren bağ dokusunu oluşturur. Bağ yapısı içindeki kondroblast ve iğsi yapıdaki fibroblast benzeri hücrelerin proliferasyonu, vasküler infiltrasyon ve bunu izleyen enkondral kemikleşme, zamanla matür lamellar kemiğe dönüşerek spinal kanalda daralmaya neden olur (Şekil 1). Bu durumun gelişmesinde, kollajen ve bağ dokusunu düzenleyen çeşitli genlerdeki polimorfizmin etkili olduğu düşünülmektedir. ${ }^{[4-7]}$

PLLO saptanan hastalar, sıklıkla $50-60$ yaş aralığındadır ve erkeklerde bayanlara oranla iki kat daha fazla görülür. Tanı konulduğunda, hastaların bir çoğunda miyelopati bulgularının başladığı gözlemlenir (Tablo 1). Ancak, bu hastaların yaklaşık \%15'inin bulguları akut travma sonrası başvurularında saptanır.

Cerrahi tedavi, Nurick Grade 3 veya 4 miyelopati bulguları saptanan hastalar için uygulanır. ${ }^{[8,9]}$ Cerrahi, anterior ya da posterior yaklaşımla uygulanabilir. Anterior yaklaşımda, tipik olarak diskektomi ve korpektomi sonrası ossifiye bağın eksizyonu uygulanır. Anterior cerrahinin avantajı, ilerlemiş bulgusu olan hastalarda (kanalın \%60'ından fazlasını içeren stenoz) direkt ve efektif kanal dekompresyonu uygulama imkanı vermesidir. Dezavantajlar olarak; C2 seviyesi ve üstüne dekompresyon uygulanamaması ve yüksek komplikasyon oranı sayılabilir.

Anterior cerrahide, spinal kanal direkt olarak ossifiye PLL'nin çıkartılması ile dekomprese edilir ve

- Illetişim adresi: Dr. Görkem Kıyak, Academic Hospital Hastanesi, Nuhkuyusu Cad. No: 94, Üsküdar, İstanbul Tel: 0216 - 6510000 e-posta: drgorkemkiyak@gmail.com

- Geliș tarihi: 5 Nisan 2017 Kabul tarihi: 5 Nisan 2017 


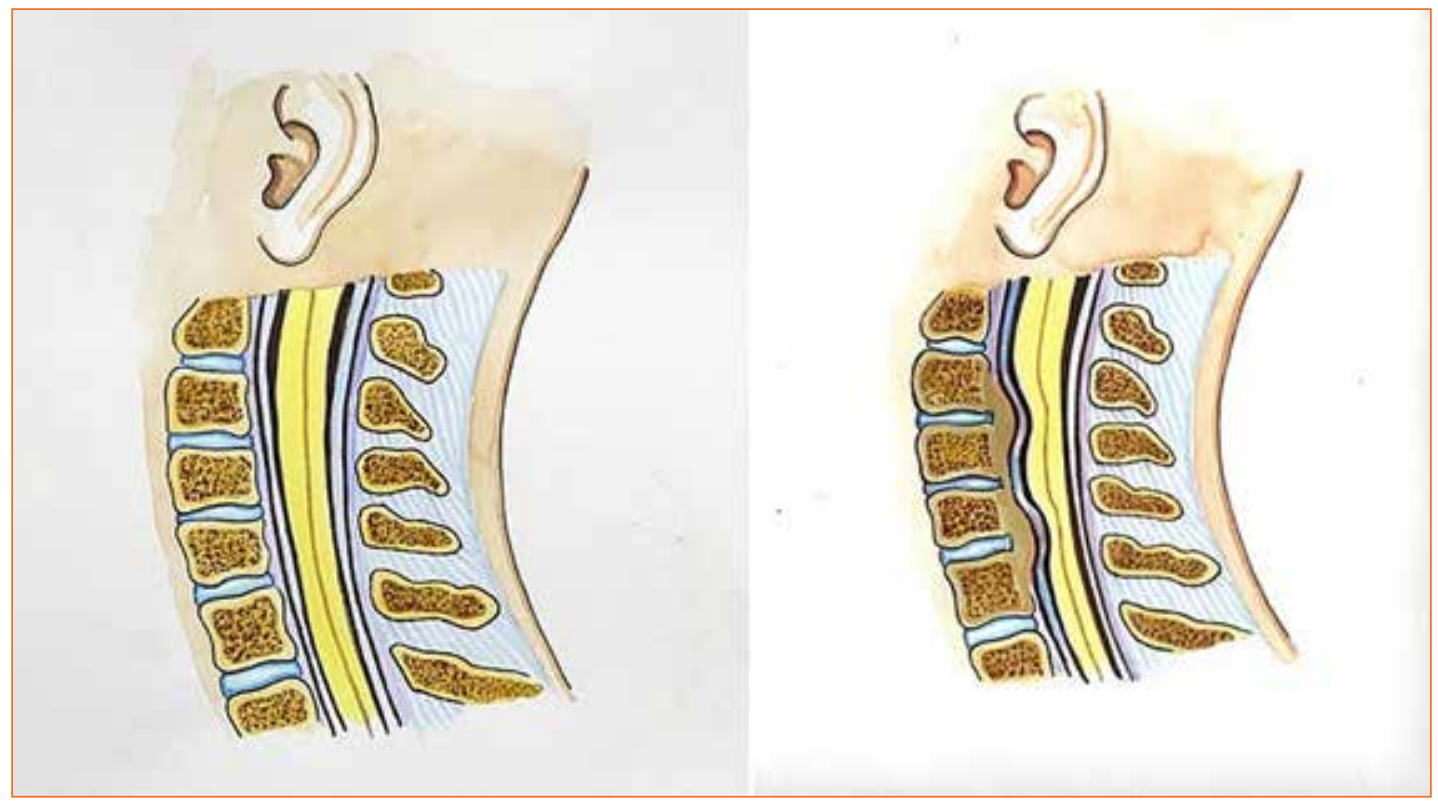

Şekil 1. PLL ossifikasyonuna bağlı spinal kanal daralması.

etkilenen seviyelere füzyon uygulanır. Bununla ilgili yapılan yayınlarda, posterior cerrahiye oranla daha etkili dekompresyon sağlandığı ve servikal lordozun korunmasında posterior cerrahiye göre daha etkili olduğu bildirilmiştir. ${ }^{[10,11]}$ Ayrıca, cerrahi yaklaşım itibariyle, aynı anda intervertebral disk patolojilerine de müdahale olanağı sağlamaktadır. C2 seviyesi ve üstüne müdahale olanağı bulunmaması, yüksek psödoartroz oranı ve üç ya da daha fazla seviye dekomprese edildiğinde operasyon sonrası disfaji görülmesi, temel cerrahi komplikasyonlar olarak karşımıza çıkmaktadır. Ayrıca, anterior cerrahi müdahale sırasında dural kese yırtıkları daha sık görülür ve yaklaşık \%15 gibi bir sıklık bildirilmektedir. [11-13]
Cerrahide, standart Smith-Robinson yaklaşımı kullanılır ve ossifiye bağ seviyesinin genişliğine göre, diskektomi, hemikorpektomi ya da subtotal korpektomi uygulanır. Üçten fazla seviyeye korpektomi başarıyla uygulanabilse de, art arda gelen üç seviyede devamlı dekompresyon uygulandığında genellikle komplikasyon ve bu komplikasyonlara bağlı reoperasyon riski $\operatorname{artar}^{[12,14]}$

Cerrahi sırasında, vertebra korpusu çıkartıldıktan sonra ossifiye bağa ulaşılarak, mikroskop büyütmesi ya da kuvvetli bir loupe magnifikasyonu ile bağın hemen altındaki dural keseden serbestleştirilmesi gerekmektedir. Bu işlem sırasında, sıklıkla kuvvetli yapışıklıklar

Tablo 1. Nurick miyelopati klasifikasyonu
o Kord disfonksiyonu bulgusu yoktur.
1 Spinal kord basısı olmasına rağmen yürüyüş ve denge normaldir.
2 Günlük işlerini kısıtlayacak kadar yürüyüş ve denge problemi var, ancak desteğe ihtiyaç duymaz.
3 Günlük işlerini kısıtlayacak kadar yürüyüş ve denge problemi var, ancak desteğe ihtiyacı vardır.
4 Destek olmadan yürümesi mümkün değildir.
$5 \quad$ Tekerlekli sandalye ya da yatak bağımlısıdır. 


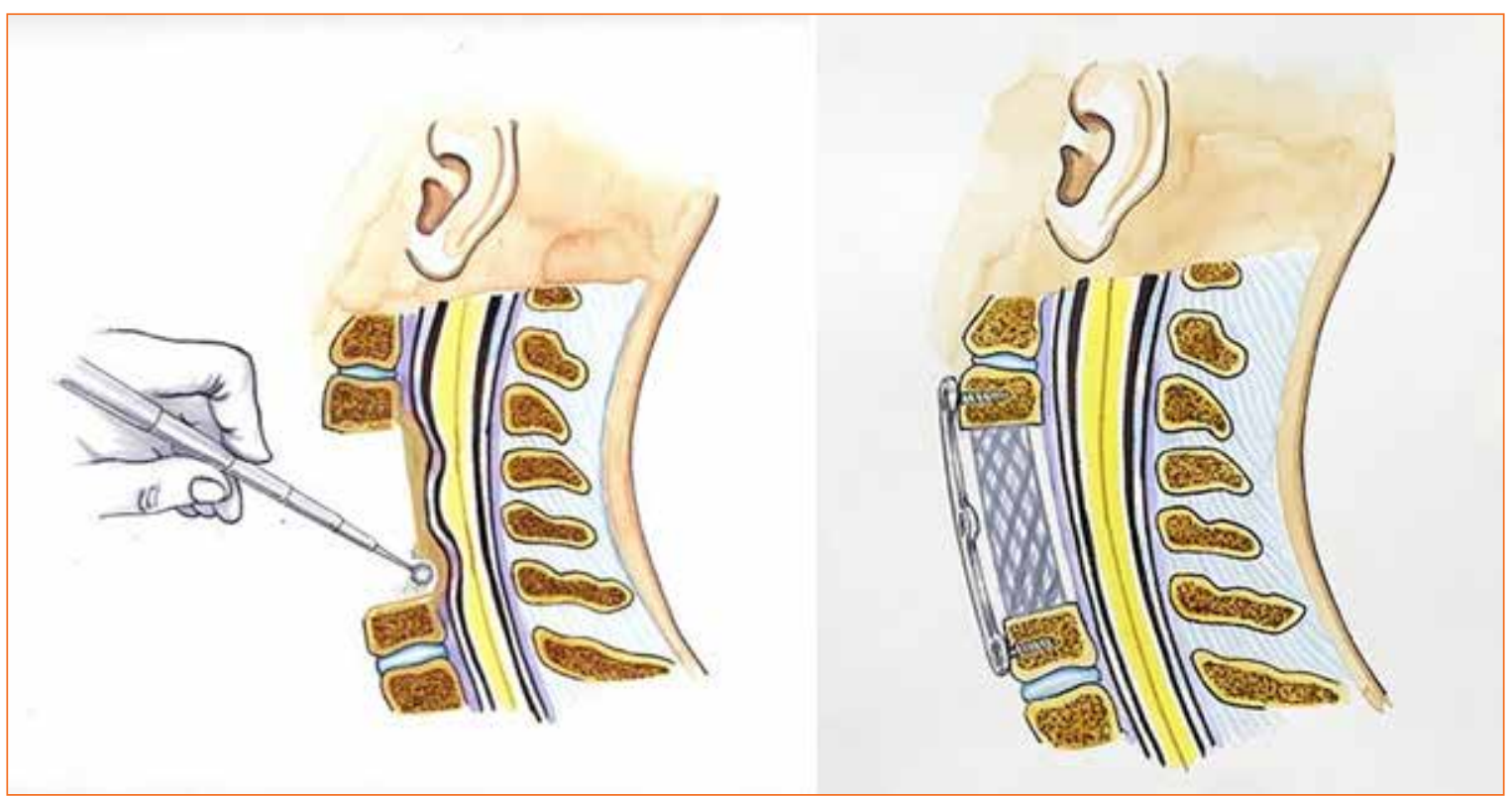

Şekil 2. Anterior dekompresyon ve kafes kullanımı ile stabilizasyon.

bulunduğundan, özellikle dikkatli olunması gerekir. Dura yırtıkları bu aşamada oluşmaktadır. Etkili bir biçimde dekompresyon uygulamak için, ossifiye bağ temizlendikten sonra anterior dural kesenin öne doğru taşma yaptığının gözlemlenmesi şarttır. Daha sonra, kafes ya da yapısal greftler kullanılarak artrodez işlemi uygulanır (Şekil 2).

Komplikasyonlar genellikle üç şekilde oluşur:

- Cerrahi yaklaşım sırasında yakın anatomik yapılara verilen zarar veya bası nedeniyle oluşanlar (disfaji, disfoni).

- Dekompresyon sırasında iyatrojenik yaralanmaya bağlı olanlar (dural kese yırtılması, C5 kök yaralanması).

- Füzyon oluşumunda yaşanan gecikmeye bağlı olanlar (greftin yerinden oynaması, psödoartroz).

Sinir kökü hasarına bağlı komplikasyonlar, anterior yaklaşımla gerçekleştirilen operasyonlar sonrası \%4 ile \%17 arasında değişen oranlarda gözlemlenmiştir. ${ }^{[3,14-16]}$ Hastalarda, sıklıkla C5 kökünü ilgilendiren motor kuvvet kaybı, parastezi ve ağrı şikayetleri görülür. Bu durumda, dekompresyonun yeterli düzeyde yapılıp yapılmadığını kontrol etmek için manyetik rezonans (MR) görüntüleme ve bilgisayarlı tomografi (BT) tetkikleri yapmak gereklidir. Eğer görüntülemede yeterli dekompresyon yapıldığı onaylanırsa, tedaviye konservatif olarak devam etmek uygun olacaktır. ${ }^{[14,16]} \mathrm{BT}$ ve $\mathrm{MR}$ kontrolünün mutlak surette önerilmesinin nedeni, bu zor cerrahi sırasında sıklıkla yetersiz oranda dekompresyon uygulanan alanların ortaya çıkabilmesidir. Eksizyon sırasında, \%4-20 olasılıkla yapışıklığa bağlı dural kese yırtıkları oluşur. ${ }^{[3,10,14]}$ Serebrospinal sıvı kaçakları, psödomeningosel ya da fistül oluşumlarına neden olabilir. Bu durumda, menenjit, yara komplikasyonları ya da hava yolu obstrüksiyonu gibi ciddi komplikasyonların ortaya çıkması olasıdır; bu yüzden, operasyon anında fark edilen yırtıklar primer onarımla kapatılmalı; bu yapılamıyorsa, otolog faysa ya da hazır kollajen greftlerle tamir edilmelidir. Küçük deliklerden oluşan sızıntıların ise, fibrin glue gibi trombojenik kapatıcılar ile tıkanması uygun olacaktır. Yani, operasyona başlamadan önce mutlaka, dural zarı onarmaya ya da tıkamaya yardımcı olacak malzemelerin hazır olması gereklidir. Sızıntı cerrahi sonrası dönemde fark edildiğinde, şant uygulaması yararlı olur. ${ }^{[13]}$

Dural yırtık oranlarını azaltmak amacıyla, Yamaura ve arkadaşları[17], "anterior floating method" ismini verdikleri bir yöntem geliştirmişlerdir. Bu yöntemde, subtotal vertebra korpusu rezeksiyonu sonrası ossifiye posterior bağın, tam eksizyonunu yapmak yerine iyice inceltilerek, anteriora doğru spinal kanadan uzaklaşacak şekilde yer değiştirmesine izin verilir. Yazarlar, bu yöntemle hastalarının tamamında serebrospinal sıvı sızıntısının önüne geçtiklerini belirtmelerine rağmen, hastaları cerrahi sonrası çekilen BT 
ve MR görüntülerinde \%14 oranında yetersiz spinal dekompresyonu uyguladıklarını saptadıklarını bildirmişlerdir. Bu yöntemin, özellikle PLL ossifikasyonuna dural zarın ossifikasyonunun eşlik ettiği hastalarda kullanılması yararlıdır. Operasyon öncesi çekilen tomografilerde çift katmanlı kemikleşme görülen hastalarda, dural zar ossifikasyonundan şüphelenilmelidir. ${ }^{[18]}$ Bu iki ossifiye katmanı cerrahi sırasında birbirinden ayırarak disseke etmek çok güçtür ve dural zar yırtıklarının görülme sıklığını büyük oranda arttırır. Özellikle bu hastalarda, dural zar yırtıklarının engellenmesi için "anterior floating method" yönteminin kullanılması uygun olacaktır. ${ }^{[19]}$

Füzyon ile ilişkili komplikasyonlardan kastedilen, psödoartroz ve konulan strut greftlerin yerinden kaymasıdır. İki ya da daha fazla seviyeye dekompresyon uygulandığında, kuvvetli yapısal destek sağlamak için trikortikal iliak krest ya da fibula kullanılmaktadır. Son yıllarda intervertebral kafes uygulamasıyla beraber, strüktürel destek sağlamayan greft uygulamaları denenmeye başlanmıştır. ${ }^{[10]}$ Her iki tür cerrahi yöntemde de \%3-15 oranında psödoartroz oranları bildirilmiştir ve bu oran, füzyon seviyesi sayısı arttıkça yükselmektedir. ${ }^{[3,10,14]}$ Semptomatik psödoartroz oluştuğunda, revizyon cerrahisi uygulanması zorunludur ve revizyon cerrahisinde de posterior füzyon uygulanması yararlı olacaktır. Yerleştirilen yapısal greftin füzyon oluşmadan yerinden kayması (\%7-11), yeniden stenoz ya da psödoartroz gelişmesi durumunda ise revizyon cerrahisi gereklidir.

\section{KAYNAKLAR}

1. Matsunaga S1, Sakou T. Ossification of the posterior longitudinal ligament of the cervical spine: etiology and natural history. Spine (Phila Pa 1976) 2012;37(5):E309-14. Crossref

2. McAfee PC, Regan JJ, Bohlman HH. Cervical cord compression from ossification of the posterior longitudinal ligament innon-orientals. J Bone Joint Surg Br 1987;69(4):569-75.

3. Belanger TA, Roh JS, Hanks SE, Kang JD, Emery SE, Bohlman $\mathrm{HH}$. Ossification of the posterior longitudinal ligament: results of anterior cervical decompression and arthrodesis in sixty-one North American patients. J Bone Joint Surg Am 2005;87(3):610-5. Crossref

4. Inamasu J, Guiot BH, Sachs DC. Ossification of the posterior longitudinal ligament: an update on its biology, epidemiology, and natural history. Neurosurgery 2006;58(6):1027-39. Crossref

5. Koga H, Sakou T, Taketomi E, Hayashi K, Numasawa T, Harata S, Yone K, Matsunaga S, Otterud B, Inoue I, Leppert M. Genetic mapping of ossification of the posterior longitudinal ligament of the spine. Am J Hum Genet 1998;62(6):1460-7. Crossref

6. Kong Q, Ma X, Li F, Guo Z, Qi Q, Li W, Yuan H, Wang $Z$, Chen Z. COL6A1 polymorphisms associated with ossification of the ligamentum flavum and ossification of the posterior longitudinal ligament. Spine (Phila Pa 1976) 2007;32(25):2834-8. Crossref
7. Kamiya M, Harada A, Mizuno M, Iwata H, Yamada $Y$. Association between a polymorphism of the transforming growth factor - beta 1 gene and genetic susceptibility to ossification of the posterior longitudinal ligament in Japanese patients. Spine (Phila Pa 1976) 2001;26(11):1264-7.

8. Kalb S, Martirosyan NL, Perez-Orribo L, Kalani MY, Theodore N. Analysis of demographics, risk factors, clinical presentation, and surgical treatment modalities for the ossified posterior longitudinal ligament. Neurosurg Focus 2011;30(3):E11. Crossref

9. Fujiyoshi $\mathrm{T}$, Yamazaki M, Kawabe J, Endo T, Furuya T, Koda M, Okawa A, Takahashi K, Konishi H. A new concept for making decisions regarding the surgical approach for cervical ossification of the posterior longitudinal ligament: the K-line. Spine (Phila Pa 1976) 2008;33(26):990-3. Crossref

10. Mizuno J, Nakagawa $\mathrm{H}$. Outcome analysis of anterior decompressive surgery and fusion for cervical ossification of the posterior longitudinal ligament: report of 107 cases and review of the literature. Neurosurg Focus 2001;10(4):6.

11. Sakai K, Okawa A, Takahashi M, Arai Y, Kawabata S, Enomoto M, Kato T, Hirai T, Shinomiya K. Five-year followup evaluation of surgical treatment for cervical myelopathy caused by ossification of the posterior longitudinal ligament: a prospective comparative study of anterior decompression and fusion with floating method versus laminoplasty. Spine (Phila Pa 1976) 2012;37(5):367-76. Crossref

12. MizunoJ, Nakagawa $H$, Matsuo $N$, Song J. Dural ossification associated with cervical ossification of the posterior longitudinal ligament: Frequency of dural ossification and comparison of neuroimaging modalities in ability to identify the disease. J Neurosurg Spine 2005;2(4):425-30. Crossref

13. An HS, Al-Shihabi L, Kurd M. Surgical treatment for ossification of the posterior longitudinal ligament in the cervical spine. J Am Acad Orthop Surg 2014;22(7):420-9. Crossref

14. Iwasaki M, Okuda S, Miyauchi A, Sakaura H, Mukai Y, Yonenobu K, Yoshikawa H. Surgical strategy for cervical myelopathy due to ossification of the posterior longitudinal ligament: Part 2. Advantages of anterior decompression and fusion over laminoplasty. Spine (Phila Pa 1976) 2007;32(6):654-60. Crossref

15. Epstein NE. The surgical management of ossification of the posterior longitudinal ligament in 43 north americans. Spine (Phila Pa 1976) 1994;19(6):664-72.

16. Matsuoka T, Yamaura I, Kurosa Y, Nakai O, Shindo S, Shinomiya K. Long-term results of the anterior floating method for cervical myelopathy caused by ossification of the posterior longitudinal ligament. Spine (Phila Pa 1976) 2001;26(3):241-8.

17. Yamaura I, Kurosa Y, Matuoka T, Shindo S. Anterior floating method for cervical myelopathy caused by ossification of the posterior longitudinal ligament. Clin Orthop Relat Res 1999;(359):27-34.

18. Hida K, Iwasaki Y, Koyanagi I, Abe H. Bone window computed tomography for detection of dural defect associated with cervical ossification posterior longitudinal ligament. Neurol Med Chir (Tokyo) 1997;(37):173-5.

19. Chen Y, Guo Y, Lu X, Chen D, Song D, Shi J, Yuan W. Surgical strategy for multilevel severe ossification of posterior longitudinal ligament in the cervical spine. J Spinal Disord Tech 201;24(1):24-30. Crossref 